\title{
INVESTIGACIÓN/RESEARCH
}

\section{LA TELERREALIDAD A TRAVÉS DEL CINE: CRÓNICASDE SEBASTIÁN CORDERO}

Paula Requeijo-Rey ${ }^{\mathbf{1}}$ : Universidad Complutense de Madrid. España. p.requeijo@ccinf.ucm.es

\section{RESUMEN}

A finales de la década de los ochenta y principios de la de los noventa prolifera un género que ya está presente en los comienzos de la televisión: la telerrealidad. Los formatos más populares de este macrogénero son dos: el reality show y el talk show. Sin embargo, el género aglutina numerosos programas de distinto tipo que, en mayor o menor medida, presentan una serie de características. La autora parte de la idea de que la película Crónicas (2004), del director ecuatoriano Sebastián Cordero, refleja los principales rasgos de la televerdad, en concreto, de un tipo de programas: los que atienden a sucesos, accidentes, violencia. Partiendo de algunos textos de Imbert, León, Postman, Castañares y Abril analiza las características del fenómeno a través del filme. Éste se revela como un excelente instrumento a la hora de entender aspectos como la espectacularización, el predominio de lo sentimental, la convivencia de opuestos, la hibridación de géneros, la confusión de la esfera pública y la privada y el nuevo papel del presentador.

PALABRAS CLAVE: Telerrealidad - Principales rasgos - Cine - Crónicas - Sebastián Cordero.

\footnotetext{
${ }^{1}$ Autor Correspondiente:

Paula Requeijo-Rey: Investigadora en la Facultad de Ciencias de la Información. Universidad Complutense de Madrid. España

Correo: p.requeijo@ccinf.ucm.es
} 


\title{
REALITY TV THROUGH CINEMA: CRÓNICAS BY SEBASTIÁN CORDERO
}

\begin{abstract}
In the late eighties and early-nineties a genre that almost appeared with the beginning of television proliferates: reality TV. The most popular formats of this macrogenre are two: the reality show and the talk show. However, reality TV draws together many different types of programs that meet a number of features to a greater or lesser extent. The author considers that the movie Crónicas (2004), by the Ecuadorian director Sebastián Cordero, reflects the main features of reality TV. Based on texts from authors like Postman, Imbert, León, Abril or Castañares she analyses the characteristics of this phenomenon through the film. It is revealed as an excellent tool for understanding aspects such as spectacle, the predominance of feelings, the coexistence of opposites, genres mixing, the confusion of public and private spheres and the new role of the presenter.
\end{abstract}

KEY WORDS: Reality TV - Main features - Cinema - Crónicas - Sebastián Cordero.

\section{INTRODUCCIÓN}

\subsection{La telerrealidad}

Los críticos coinciden en que la telerrealidad (Reality TV) prolifera y se desarrolla, sobre todo, a finales de la década de los ochenta y principios de los noventa. Los formatos que se encuadran dentro de ella son muy variados y diferentes pero en mayor o menor medida presentan una serie de características. Se centran en sucesos, acontecimientos, vivencias, acciones... protagonizadas por personas reales, gente común y corriente. Lo íntimo, lo personal, es el objeto preferente de muchos de estos programas. De esta forma, lo que tradicionalmente se ha enmarcado dentro de la esfera privada se traslada a la pública. Con independencia del contenido (asesinatos, accidentes, relaciones de pareja, etc.) se tiende a la espectacularización y la dramatización, con un dominio claro del componente emotivo. El objetivo es entretener a la audiencia.

En un primer momento, el concepto hacía referencia "a programas de policías (Cops) $y$ de reconstrucciones (America's Most Wanted)". Sin embargo, la aparición de nuevos formatos a principios de los 90 hizo que el término se ampliara para incluirlos. La complejidad a la hora de "delimitar con precisión" qué es la telerrealidad reside en una de sus principales características: la hibridación de géneros (León, 2009, p. 14). Se mezclan géneros informativos como la entrevista o la crónica con otros de ficción en programas de entretenimiento. 
Bienvenido León (2009, p. 15) propone una clasificación de los programas de telerrealidad basándose en su contenido. Distingue cinco categorías principales:

a) Accidentes y crímenes. Cita dos series documentales que se emiten desde los años 80: Crimewatch y Cops.

b) Ayuda social. El espacio Queen for a Day (Reina por un día) emitido por la NBC entre 1956 y 1964 sirve de ejemplo para los que vendrían después.

c) Intervenciones en la vida de las personas. "Enseñan a ciudadanos corrientes a manejar sus propias vidas y a solucionar problemas" (León, 2009, p. 15). Hay numerosos ejemplos: desde programas que enseñan a los padres cómo educar a sus hijos hasta otros que indican cómo resolver relaciones de pareja.

d) Convivencia y relaciones personales. El más popular es Gran Hermano (Big Brother).

e) Formación artística. Los concursantes aprenden a cantar, bailar, actuar, etc.

El éxito de todos ellos está relacionado con el interés por lo auténtico, lo real, que sustituye a la atracción por lo verosímil, lo creíble. Estos programas se presentan como diferentes porque dicen ofrecer la verdad. No hay actores o guiones. La lente de la cámara recoge la vida misma.

Sin embargo, la idea de ser simplemente un espejo de lo real es una ilusión bajo la que subyace un acto creativo. La televisión no representa la realidad sino que diseña la suya propia. Lo hace a través de la ya mencionada hibridación de géneros, de la dramatización y la espectacularización. Así es como el espectador toma "como realidad algo perfectamente manipulado (en términos objetivos) por el medio, es decir, algo totalmente controlado como forma narrativa al margen de la evolución más o menos espontánea de la historia que se va construyendo ante nuestra mirada" (I mbert, 2003, p. 31). En el fondo, lo verosímil sigue dominando porque el espectador simplemente acepta lo que ve, lo que aparece en la pantalla.

Gérard I mbert señala la hipervisibilidad como otra de las características esenciales de la telerrealidad. Consiste en "la extensión, exacerbación y degradación de la categoría de lo informativo" (Imbert, 2003, p. 70). La televisión puede ocuparse de cualquier suceso, acontecimiento o asunto y dentro de éste, atender a cualquier detalle del mismo. No hay lugar para la cautela o la reserva. De ahí que se trate lo íntimo, lo doloroso y lo violento.

\section{METODOLOGÍA}

La metodología empleada se basa fundamentalmente en el método inductivo, desde el análisis de las particularidades de la película Crónicas de Sebastián Cordero hasta la conseguir concretar los principales rasgos de la telerrealidad.

Se trata de crear un marco de actuación y análisis a partir de una estructura epistemológica basada en un caso concreto que se pretende universalizar como modelo para nuevos trabajos.

\section{ANÁLISIS Y DISCUSIÓN}




\section{1 Antecedentes}

Como hemos indicado, se considera que la década de los 90 es un momento clave a la hora de determinar el desarrollo y el auge de la telerrealidad. Sin embargo, rasgos propios de este macrogénero como la espectacularización, la exposición de lo privado o la representación de la persona común y corriente ya están presentes antes.

Para Neil Postman (1991, p. 68) la era del mundo del espectáculo nace a finales del siglo XIX con la asociación del telégrafo y la prensa. El telégrafo permite enviar una cantidad de información limitada en un espacio de tiempo corto desde largas distancias. Así, la importancia del contenido disminuye y el objetivo es únicamente comunicar datos, aunque estos carezcan de utilidad para las personas que los reciben. La información pasa a ser "un producto de consumo, una cosa, que se podía comprar o vender sin tener en cuenta sus usos o su significado" (Postman, 1991, p.70). Uno de los principales defectos que se atribuye a la televisión, la descontextulización, la falta de antecedentes, conexiones e implicaciones, caracteriza ya la forma de tratar la información que deriva de la convergencia telégrafo- periódicos.

Gonzalo Abril cree que el acercamiento a lo privado por parte de "la gente común" y su aparición en televisión manifiestan "una doble tendencia de la comunicación masiva" que Walter Benjamin señaló en los años 30: "la búsqueda de proximidad y la aspiración de las masas a ser representadas (filmadas)". En los años 90 la televisión materializa una de las observaciones sobre el futuro más conocidas de Andy Warhol: todo el mundo será famoso durante 15 minutos. Se cumple no sólo porque así lo quiere el medio sino porque hay una "sensibilidad o disposición del público" para ello (Abril, 1995, p. 93).

Es interesante el planteamiento sobre la individualización que menciona Abril siguiendo a Pierre Chambat y Alain Ehrenberg. El origen de la misma está en el aumento de las situaciones inestables, transitorias:

En esta situación de fragmentación en que lo provisional y lo incierto se multiplican (..) la imposición de normas claras de autoridad [...] pierde sentido y legitimidad [...]. En revancha, la autonomía se convierte en una constricción de masas -no es sólo una elección o una aspiración- para señalarse y actuar en una sociedad fragmentada. Fragiliza a los individuos que cargan con responsabilidades sostenidas en otra época por instancias colectivas [...]. Esta incertidumbre generalizada [...] hace hoy día difíciles de discernir las fronteras de un espacio privado y de un espacio público cuyos contenidos en verdad ya no se saben definir. De ahí este proceso generalizado de privatización de lo público: el individuo es la caja de resonancia de todo (Chambat y Ehrenberg en Abril, 1995, p. 95 y 96)

En esta misma línea, Imbert apunta que la crisis de la historia, de las ideologías y de lo político está en el origen de la proliferación de la telerrealidad (Imbert, 2003). 


\section{2 Crónicas de Sebastián Cordero}

Crónicas es el segundo largometraje del realizador ecuatoriano Sebastián Cordero. Lo produce en el año 2004, aunque en España se estrena tres años más tarde, en junio de 2007. El actor J ohn Leguizamo interpreta a Manolo Bonilla, reportero para un canal de televisión que, con sede en Miami, emite en varios países de Sudamérica. El programa en el que trabaja, Una hora con la verdad, es un espacio de telerrealidad que se centra en violencia, accidentes y crímenes. Sus protagonistas atraviesan situaciones límite y ofrece imágenes impactantes, escalofriantes en algunos casos.

Manolo viaja hasta una ciudad de Ecuador, Babahoyo (capital de la provincia de Los Ríos y a unos sesenta kilómetros aproximadamente de Guayakil) para cubrir el caso del "Monstruo de Babahoyo". Se trata de un violador y asesino en serie que ha acabado con la vida de decenas de niños. Le acompañan su productora, Marisa (Leonor Watling) y un cámara, I ván (J osé María Yazpik). Asisten al funeral de tres de los pequeños asesinados con una doble intención: obtener imágenes dramáticas y conseguir una entrevista con alguno de los familiares.

Vinicio Cepeda (Damián Alcázar), un repartidor de biblias y catecismos, atropella con su coche al hermano de uno de los niños asesinados, al que Manolo trata de convencer para que hable ante la cámara. Varios vecinos y el padre de la víctima, Don Lucho (Henry Layana), intentan linchar a Vinicio.

El vendedor ingresa en prisión al igual que Don Lucho y hasta allí se desplazan Manolo y su equipo. Vinicio le ofrece al reportero un trato: le proporcionará información sobre "El Monstruo" a cambio de que emita un reportaje sobre su caso.

Tras consultar varios manuales (Postman, 1991, Imbert, 2003, León, 2009) y artículos (Abril, 1995, Castañares, 1995) sobre televisión y telerrealidad hemos comprobado, como exponemos a continuación, que la película ejemplifica de forma muy clara los principales rasgos de este fenómeno. En concreto, se ocupa de un tipo de programas: los que atienden a sucesos, accidentes, violencia y, en general, a todo lo anómico y lo impactante.

\subsection{Análisis}

Atendiendo al objetivo de este artículo, demostrar cómo el filme ejemplifica algunos de los principales rasgos de la telerrealidad, hemos elegido varios momentos de Crónicas:

a) El entierro y el intento de linchamiento.

b) La emisión de Una hora con la verdad.

c) La visita a la cárcel, grabación y emisión del reportaje sobre Vinicio.

\subsubsection{Entierro e intento de linchamiento}


Durante la celebración del entierro, Manolo observa atentamente, camuflado entre la gente, junto a Marisa. La madre de uno de los niños llora, besa y abraza el ataúd cerrado que contiene el cuerpo de su hijo. Su marido la consuela y trata de alejarla del féretro. Iván, que ha estado grabando la escena desde muy cerca, se aproxima al marido para apartarle de ella porque no le permite obtener un primer plano de la mujer.

Manolo le pide a Marisa que consiga una entrevista con una de las madres y ella sugiere hacer también una al hermano o a un compañero de clase de alguna de las víctimas. Suena el teléfono móvil de Marisa y ella no duda en cogerlo.

Mientras tanto, Manolo ve cómo uno de los niños que está allí se aleja de la zona del cementerio en la que se celebra el funeral y lo sigue. Cuando están solos, averigua quién es. Se trata de Joseph Juan, el hermano gemelo de una de las víctimas. El periodista no pierde el tiempo:

Manolo: Cuando regrese la cámara tienes que contarme todo lo que se te venga a la mente y tranquilo, yo te guío con mis preguntas y quiero que sepas, primero que nada, que yo soy tu amigo. Quiero saber solamente qué fue lo que pasó. Y a mí me puedes decir lo que sea. ¿Confías en mí?

Joseph Juan sale corriendo del cementerio detrás de un amigo que juega con una pelota. Vinicio, el padre de uno de sus compañeros de la escuela, lo atropella con su camioneta y muere. La gente comienza a agolparse alrededor del fatal accidente. El padre de Joseph J uan, Don Lucho, que acaba de enterrar a uno de sus hijos, descubre que está muerto. Vinicio sube a la camioneta, pero algunos de los hombres que están allí lo sacan fuera de ella y comienzan a golpearle. Un coro de personas da ánimos a los agresores, que ya han cogido una cuerda con intención de ahogar a Vinicio. Es un intento de linchamiento.

Marisa avisa a Manolo de que la madre de Joseph Juan está allí mismo. Él le indica a I ván que deje el linchamiento y se centre ahora en ella, que camina desconcertada, en estado de shock, con el cuerpo de su hijo en brazos.

Don Lucho, lleno de rabia y furia, corre hacia Vinicio y lo golpea sin piedad. I ván se introduce en medio del grupo y recoge todos los detalles con su cámara. Don Lucho ha encontrado un bidón de gasolina, se la echa por todo el cuerpo, enciende una cerilla y le prende fuego. Parece que la muerte de Vinicio está próxima. I ván se acerca todo lo que puede.

El hijo de Vinicio, Robert, va, desesperado, en busca de su madre. Ella trata de acercarse a su marido pero la masa se lo impide. Manolo ordena a Iván que lo grabe $y$, acto seguido, interviene para que dejen pasar a la mujer. Vinicio consigue apagar las llamas de sus ropas pero los agresores le atan con cuerdas y le echan más gasolina. Su mujer lo abraza entre lágrimas. Manolo agarra a Don Lucho, forcejea con él y, finalmente, la policía se los lleva a él y a Vinicio. La mujer de Vinicio abraza 
desesperada a sus dos hijos. I ván continúa grabándolo todo y cuando se aseguran de que hay suficiente material para montar un programa se marchan.

Iván es el ejemplo perfecto de lo que se conoce como vídeo-buitre. "Se trata de una persona que, cámara en mano, recorre las calles a la sombra de los servicios de emergencia, con la esperanza de recoger imágenes escabrosas que después pueda vender a las cadenas de televisión" (León, 2009, p. 18). La diferencia es que él no ha de ir tras los servicios de emergencia porque ya tiene a Manolo y Marisa para indicarle dónde encontrar imágenes aterradoras. Tampoco debe buscar a alguien que se las compre porque los responsables de Una hora con la verdad están ansiosos por recibirlas.

Víctor y Marisa tienen una actitud similar. Asisten al entierro y al linchamiento sin inquietarse porque les domina una única idea: conseguir el material más conmovedor e impactante para su programa. Poco después de la emisión del mismo, I ván se lamenta de no haber conseguido poner a Joseph Juan frente a la cámara justo antes de morir. De esa forma, el efecto dramático hubiera sido mayor y la audiencia también: "Qué cabrón estuvo lo del chavito de hoy [...] ¿Se imaginan el madrazo que hubiera sido eso? Primero la entrevista con el chavito, después el accidente y luego el linchamiento. Hubiéramos alcanzado unos ratings altísimos".

Los tres personajes representan la obsesión de la televisión hiperrealista por "querer captar in situ y en vivo el detalle morboso o la explosión emotiva, buscando permanentemente el efecto pasional, la dimensión compasional [...]". Se tratan todo tipo de temas y se emiten todo tipo de imágenes: "Lo tengo todo, lo tengo todo: la patada en el culo, el hombre ardiendo, todo" (Iván a Manolo). El único requisito es que sean de actualidad. Es lo que Imbert llama "un querer ver sin límites ( $n$ i espaciales, ni referenciales, ni simbólicos, ni tampoco éticos)" (I mbert, 2003, p. 63, 70-71).

Se aprecia claramente cómo Manolo interviene directamente en los acontecimientos para que se desarrollen como él desea. Obliga a apartarse a aquéllos que impiden a la mujer de Vinicio acercarse a él y agarra a Don Lucho hasta que la policía se lo lleva. De esta forma, consigue una imagen emotiva (la de Vinicio y su mujer fundiéndose en un abrazo desesperado mientras tratan de lincharlo) y salva a Vinicio de la muerte convirtiéndose en un héroe. La televisión desarrolla el papel de salvadora, como poco después subraya el conductor de Una hora con la verdad. Lejos de reflejar simplemente lo que ocurre la televisión recoge acontecimientos que ella misma ha provocado "porque sin ella no ocurrirían" (Castañares, 1995, p. 110 y 111). Como Manolo le recuerda a Marisa más adelante: "Estamos al borde de algo muy importante. Y esta historia no existiría sin nosotros". El reportero no ha atropellado a Joseph Juan ni ha comenzado el linchamiento pero sí ha evitado que se produzca la muerte de Vinicio como si fuera un representante de la ley aunque con un interés espurio.

Manolo es un personaje de ficción, pero hay casos reales que lo superan como el del político y presentador brasileño Wallace Souza. Para aumentar los índices de audiencia 
del reality de crímenes que dirigía, Canal Livre, organizaba los asesinatos de los que después informaba (León, 2009, p. 19 y Vargas Llosa, 2009).

\subsubsection{Emisión de Una hora con la verdad}

Un ojo en primer plano con los títulos de crédito sobre el mismo y una música impactante dan paso a la voz del conductor de Una hora con la verdad, Hugo Víctor Puente:

Hugo Víctor: Sólo un programa tiene el valor de presentarle el mundo en su verdadero estado actual. Sólo un programa no parpadea cuando la noticia hace impacto. Esta noche, amigos televidentes, Una hora con la verdad sigue la pista al tristemente célebre "Monstruo del Babahoyo", violador de niños y asesino en serie, que aterroriza a Ecuador desde hace un año y medio. El descubrimiento de la fosa con cadáveres de 12 niños y niñas" [se muestran imágenes de fosas y cuerpos], todos torturados y violados, tiene a la ciudad de Babahoyo en un estado de shock [imagen de una persona que muestra el zapato de una de las víctimas con expresión de desconcierto y otro que se tapa la cara con la camisa]." Declaraciones del policía Olivar Rojas: "Los cuerpos de los niños muestran claros signos de que antes de su muerte sufrieron violencia física y sexual, incluyendo tortura.

Presentador: Los Santos Inocentes', como se conoce a los niños desaparecidos son ya más de 150. Y en la primicia de hoy, nuestro reportero Manolo Bonilla logra detener un violento linchamiento mientras la policía local no se decide a intervenir [se muestran algunas de las imágenes más terribles que Iván ha grabado: el cuerpo de Vinicio en llamas y su mujer desesperada tratando de acercarse a él para socorrerle con una música que sugiere peligro]. Y eso no es todo. Una hora con la verdad se complace en anunciarles que la semana que viene habrá una entrevista exclusiva con los rehenes de Medellín. Y prometen contárnoslo todo [detrás del presentador se muestra la imagen de un hombre con un pasamontañas negro que sujeta la cabeza de otro que está cubierto con un trapo blanco]. Esto y más en Una hora con la verdad.

Hugo Víctor Puente presume de que son los únicos que se atreven a mostrar "el mundo en su verdadero estado actual". Este es el principal argumento que esgrimen los defensores de la telerrealidad: se ofrece únicamente la verdad, lo auténtico. Sin embargo, esta autenticidad está cuidadosamente fabricada, como exponemos a continuación.

En tan sólo un minuto y 40 segundos el presentador utiliza 21 términos relacionados con el terror, la muerte y la violencia: cadáveres, violados, violador, cuerpos, fosa, tortura, linchamiento, rehenes, etc. Se sirve de figuras como la repetición ("Sólo un programa tiene [...] Sólo un programa no parpadea [...]") o el contraste (el "Monstruo de Babahoyo" y "Los Santos Inocentes"). 
La comunicación no verbal que emplea despierta en el espectador sensación de inquietud. Su tono general es de alarma, subraya determinadas expresiones (por ejemplo, "estado de shock") a través de una entonación especial y su ritmo es rápido. Utiliza numerosos ilustradores como el índice alzado, las palmas adentro, el toque índice-pulgar, y los movimientos de cabeza y de cejas en un período de tiempo muy breve.

Mientras habla se muestran varias imágenes: a) una imagen fija en tonos azules y naranjas que simula un incendio; sobre ella pasan rápidamente palabras como: "tortura", "fuga", "hampa", "justicia", "venganza" o "sociedad"; la que más resalta es "compromiso" (deducimos que sugieren "compromiso con la verdad"); b) fosas, cuerpos de niños, una persona que muestra el zapato de una de las víctimas con expresión de desconcierto y otro que se tapa la cara con la camisa; c) el cuerpo de Vinicio en llamas y su mujer desesperada tratando de acercarse a él para socorrerle; d) un hombre con un pasamontañas negro que sujeta la cabeza de otro que está cubierto con una tela blanca.

La música es fundamental en este tipo de espacios porque contribuye a "crear un estado de ánimo" (Postman, 1991, p. 106). Aquí es de ritmo rápido para provocar tensión en el espectador. El objetivo de toda esta puesta en escena es la espectacularización de un objeto ya de por sí terrible.

Los realities sobre asesinatos y accidentes como Una hora con la verdad se hacen populares a finales de la década de los ochenta (León, 2009, p. 18). Se sirven de lo que Imbert califica como "referentes fuertes" que coinciden con las tres S: sexo, sangre y sensacionalismo. El autor se pregunta: "¿podríamos añadir muerte?" (I mbert, 2005). Nosotros respondemos: desde luego. En Una hora con la verdad se reflejan perfectamente las tres $\mathrm{S}$ y la $\mathrm{M}$ (de muerte). Se habla de niños que han sido violados y asesinados mientras se muestran las fosas en las que han aparecido varios de los cuerpos. Todo (el contenido, las imágenes, el paralenguaje del presentador, la música) está al servicio del sensacionalismo. No hay límites a la hora de impresionar, de impactar a la audiencia para mantener así su atención. De ahí que se seleccionen objetos "que por sus características extremas fomentan el voyeurismo (el placer del ver por el ver) y alimentan el morbo (el deseo de ver cada vez más)" (Imbert, 2005).

El televidente se siente atraído hacia estos acontecimientos desagradables porque lo conectan "con lo más profundo y oculto de sus tensiones y pulsiones [...] La televisión seduce porque es espejo [...] de la realidad interna del que la contempla" (Ferrés en Imbert, 2003, p. 45).

Es fácil identificarse con el protagonista "porque él es nosotros, cualquiera de nosotros" (Castañares, 1995, p. 116). Todos podrían ser padres de esos niños a los que "El Monstruo de Babahoyo" ha violado y asesinado. Todos podrían ser Vinicio, que accidentalmente atropelló con su coche a un niño que se cruzó en su camino. Todos, como Don Lucho, sentirían rabia hacia el hombre que provocó la muerte de su hijo. 
Otro rasgo de la telerrealidad que se refleja en el breve espacio de tiempo que se dedica a Una hora con la verdad es el desempeño de funciones que corresponden a otros poderes o instituciones. El presentador explica que "Manolo Bonilla logra detener un violento linchamiento mientras la policía local no se decide a intervenir". Si las fuerzas de seguridad no están capacitadas para cumplir con su cometido, está la televisión, representada por la figura de Bonilla, para hacerse cargo.

\subsubsection{Visita a la cárcel, grabación y emisión del reportaje}

El padre de Joseph Juan y de uno de los niños asesinados por "El Monstruo de Babahoyo", Don Lucho, está en la misma prisión que Vinicio. Ha intentado asesinarlo.

El reportero y su equipo llegan a la cárcel. I ván comienza a grabar a los presos en el patio hasta que da con Vinicio. Está en una esquina, cubierto únicamente por una especie de taparrabos y por sus propias heces. Es la forma de evitar que Don Lucho y otros presos se le acerquen e intenten matarlo. Uno de los guardas ordena a Vinicio que vaya a lavarse. Iván lo sigue y registra la acción con su cámara. Mientras tanto, Manolo prepara a Don Lucho para una entrevista:

Manolo: No tengas miedo de contarme todo. Yo quiero que le digas a la cámara lo que has vivido estos últimos meses desde que despareció tu primer hijo. Quiero que me digas lo que sentiste cuando supiste que tu otro hijo había sido atropellado.

Después se encuentra con Vinicio, que le pide que grabe un reportaje sobre todo lo que le ha ocurrido. El preso es consciente de la influencia de la televisión y de cómo debe enfocarse la pieza para afectar al juicio de la audiencia. Vinicio: "Si muestra el peligro que vivo aquí dentro [...] Mi mujer está a punto de dar a luz, mi hijo está casi abandonado. Usted sabe cómo están las cosas ahí fuera con 'El Monstruo".

Manolo no parece querer ayudarlo hasta que éste le explica que tiene información sobre "El Monstruo de Babahoyo". Le proporciona un dato clave: cerca de donde se aloja hay una fosa que la policía no ha descubierto. Contiene el cuerpo de una niña de nueve años. Va con I ván hasta el lugar que le ha indicado, comprueba que lo que le ha dicho es cierto y registran las imágenes en la cámara.

El periodista intuye que Vinicio es "El Monstruo" y accede a hacer el reportaje con la intención de obtener después una confesión suya ante la cámara.

La pieza combina las imágenes más duras y emotivas del linchamiento con otras de Vinicio en la cárcel, las declaraciones de un médico dando detalles de cómo se produjo la muerte de J oseph J uan y varias entrevistas: a) La de la mujer de Vinicio, Esperanza, que está embarazada, la cual habla sobre la personalidad de su marido, "amistosa" y "juguetona": eso hace que los niños lo quieran y es uno de los motivos por los que se enamoró de él; b) la de Robert, el hijo adoptivo de Vinicio: sentado en el regazo de este último explica cómo encontró a su amigo J oseph Juan muerto y cómo la policía 
se llevó a Vinicio: "Sentí que nunca volvería a ver a mi padre"; c) la de Don Lucho, que recuerda cómo nacieron sus hijos y el momento en que uno de ellos desapareció: “Mi esposa no podía tener hijos. [...] Un día llegó el milagro y fuimos doblemente bendecidos [...] Los meses de la búsqueda fueron terriblemente difíciles [...] ¿Usted sabe lo que "El Monstruo" ese le hizo a mi niño? [...] Yo ya no tengo futuro para vivir"; d) las de los vecinos de Vinicio, que lo consideran una excelente persona: es el héroe del barrio; e) la del propio Vinicio, que cuenta su historia e insiste en que está encarcelado por un desafortunado accidente.

Manolo finaliza el reportaje a modo de conexión en directo frente a la cárcel:Manolo: "Su esposa tendrá un hijo en unos días. Será el primer hijo de Vinicio pero no podrá estar allí. Desde Babahoyo, Ecuador, para Una hora con la verdad, Manolo Bonilla."

Observamos cómo se construye la pretendida autenticidad de Una hora con la verdad a través de las preguntas que Manolo y su equipo hacen a los entrevistados y del montaje de la pieza. Le piden a Don Lucho que les diga cómo se siente tras la muerte de sus dos hijos, a Esperanza que recuerde cómo se enamoró de Vinicio y a Robert cómo se desarrolló el atropello y qué sintió al ver que se llevaban a su padre adoptivo esposado. Contenido y forma buscan desesperadamente "los efectos lacrimógenos" propios del "melodrama" (Abril, 1995, p. 98). El objetivo es crear un espectáculo con el que entretener a la audiencia (Postman, 1991, p. 91, Imbert, 2003, p.16 y León, 2009, p. 13). Las imágenes y los testimonios son fundamentalmente de tres tipos:
a) Violentos: el intento de linchamiento y Don Lucho esposado tratando de embestir a Manolo.
b) Dolorosos: la madre de Joseph Juan caminando desconcertada con el cuerpo del niño en brazos, Don Lucho explicando qué es perder dos hijos y Robert cómo fue el accidente.
c) Emotivos: Esperanza abrazando a Vinicio durante el intento de linchamiento, recordando cómo se enamoró de él, hablando del bebé que nacerá en unos días y los vecinos dando fe de lo buena persona que es, de las cualidades que tiene.

Se produce por tanto una unión de contrarios. Por un lado están el dolor, la muerte y la violencia, y por el otro el amor y la vida. Es un "mundo esquizoide" en el que conviven “deseo y repulsión, atracción y rechazo" (Imbert, 2003, p. 79).

Esperanza, Vinicio y Don Lucho no tienen reparo a la hora de hablar de sus sentimientos u ofrecer detalles de su vida privada. Parece natural revelarlos ante la cámara. Es lo que el psiquiatra Serge Tisseron denomina "extimidad": "el movimiento que nos lleva a ostentar una parte de nuestra vida íntima, tanto física como psicológica [...] Consiste en el deseo de comunicar cosas del mundo interior" (Tisseron en Imbert, 2003, p. 199). Expresar las emociones y los detalles más íntimos se convierte en una práctica habitual. La televisión lo explota hasta el punto de borrar la línea que separa la esfera privada de la pública. Antes los sentimientos y pensamientos más profundos de una persona pertenecían a su vida privada. Ahora son de los millones de televidentes que siguen el programa en el que ese individuo 
participa. La televisión se escuda en que la expresión de emociones es parte de la esencia del ser humano.

No sólo se confunde la esfera pública y la privada sino que también se mezclan géneros informativos y de ficción. Una hora con la verdad exagera los aspectos sentimentales y patéticos pero también se sirve de entrevistas, reportajes y conexiones en directo.

La obsesión por mostrarlo todo, especialmente los detalles más escabrosos, se refleja principalmente en dos momentos: cuando Iván graba a Vinicio cubierto por sus propias heces y cuando lo sigue con su cámara hasta la ducha. La televisión se convierte en el "ojo todopoderoso, omnisciente, a la que nada escapa [...]" (I mbert, 2003, p. 101-102). Sin embargo, Manolo no está satisfecho. Él desea más. Quiere introducirse "en el interior mismo de los protagonistas", en este caso de Vinicio, "sacando a la luz sus más hondos secretos" (Castañares, 1995, p. 112). Perseguirá de forma obsesiva que el preso confiese que es "El Monstruo de Babahoyo" ante la cámara.

El reportero no revela al responsable policial del caso, el capitán Rojas, que es Vinicio el que le ha facilitado la información sobre la nueva fosa ni las sospechas que le despierta. No colabora con la policía porque la ve como un estorbo. Para él son un grupo de incompetentes.

Capitán Rojas: Que usted se haga el héroe es una cosa. Que falte al respeto a la autoridad es otra.

Manolo: Capitán, ¿me está hablando del linchamiento? Porque usted y yo estábamos allí.

Capitán Rojas: ¿Cómo se atreve a decir por la tele que las autoridades no estamos haciendo nada por detener este horror? ¿Ah?

Manolo: "Yo cuestiono lo que veo. Nada más. Me parece que le faltan recursos para su causa y tal vez mis denuncias sí logren algo." Capitán Rojas: No me creo sus buenas intenciones, Señor Bonilla. Lo único que usted logra es fomentar un estado de paranoia colectiva [I ván se acerca al capitán con su cámara].

Manolo: Dígame o dígale a nuestros televidentes en toda Hipanoamérica: ¿Acaso no están desapareciendo niños? ¿No se han perpetrado crímenes atroces? ¿No se han encontrado fosas? Dígame, capitán, ¿usted tiene hijos? [tono acusador].

Considera que él tiene más capacidad para desempeñar la labor propia de las fuerzas de seguridad y las suplanta: interroga y presiona a Vinicio, visita el lugar del crimen, graba imágenes del mismo y trata de obtener una confesión. Hace ver a la audiencia que la policía, a diferencia de él, "no está haciendo nada para detener el horror". Le echa en cara al capitán Rojas su pasividad: "¿Acaso no están desapareciendo niños? Dígame, capitán, ¿usted tiene hijos?". La televisión desempeña aquí "el papel de justiciero, en un discurso arrogante que desafía los poderes públicos [...] o los sustituye" (Imbert, 2003, p. 118). Durante la emisión del programa, Hugo Víctor, el presentador, recuerda que Manolo salvó a un hombre que ahora está injustamente 
encarcelado. Es una "víctima de la burocracia y de un absurdo sistema legal". Ataca la incompetencia del poder judicial que ellos tratan de remediar con el reportaje " $E /$ perdón imposible".

Manolo estaba en contra de la emisión de la pieza porque no obtiene la confesión en cámara de Vinicio. Era su forma de chantajearle: el reportaje a cambio de la confesión. Su rabia por no haberla obtenido aumenta cuando Marisa confirma sus sospechas: los lugares y fechas de entrega de las facturas de biblias y catecismos que ha repartido Vinicio coinciden con los momentos y localizaciones en los que el asesino actuó. Al día siguiente, van hasta la cárcel para encontrarse con él pero no está allí. Esa misma mañana, el padre de Joseph Juan había retirado las acusaciones contra Vinicio y el juez que llevaba el caso llamó inmediatamente a la policía para que lo soltaran. Estos comportamientos, según explica un policía, derivan del reportaje "tan conmovedor" que había emitido Una hora con la verdad. Gracias a la labor policial y judicial de la televisión el asesino y violador queda libre.

Manolo, Iván y Marisa son los únicos que saben que Vinicio dispone de información sobre una de las fosas y los que tienen las facturas de sus ventas. Cuando se dirigen al aeropuerto de Guayaquil para volar de Ecuador a Colombia, la productora propone contarle todo al capitán Rojas, pero sus compañeros se niegan. I ván teme que les encarcelen y Manolo no está dispuesto a arriesgar su carrera hacia el estrellato. La cadena para la que trabaja acaba de ofrecerle su propio show en el que pasará de reportero a presentador.

\subsection{La figura del reportero en Crónicas}

Dentro de la clasificación sobre tipos de periodistas de cine elaborada por Juan Carlos Laviana, Manolo es un reportero amarillo (Laviana, 1996, p. 159-190) y atendiendo a la de J oe Saltzman (2002), su actitud es semejante a la de los columnistas y críticos. Sólo tiene un objetivo: conseguir exclusivas impactantes para convertirse en una persona famosa y admirada. A él no le preocupan la verdad o la justicia. En su mente sólo hay sitio para una idea: el reconocimiento. El periodismo es el instrumento para alcanzarlo. No le importa tener que renunciar a toda consideración ética o moral. Como explica el psicólogo Alfred Adler:

Tan pronto como el afán de hacerse valer prevalece, provoca en la vida del alma un aumento de tensión que hace que el hombre perciba más claramente el objetivo de poder y superioridad, y trate de aproximarse a él con movimientos reforzados, siendo entonces su vida como la esperanza de un gran triunfo (Adler, 1968, p. 158).

Él no desea transmitir información sino ser él mismo la información, aquello de lo que se habla. "Los nuevos presentadores de los programas han ido abandonando en gran parte ese distanciamiento que les caracterizaba [...] para tratar de situarse en el mismo nivel que los protagonistas del espectáculo" (Castañares, 1995, p. 115). De ahí su interés por parecer un héroe. 


\section{CONCLUSIONES}

La película Crónicas narra una historia que se desarrolla en Babahoyo, Ecuador. Sin embargo, nos permite entender los principales rasgos de un fenómeno que está presente en las televisiones de distintos países y distintas culturas de todo el mundo: la telerrealidad. Durante 108 minutos comprobamos cómo se fabrica la autenticidad en este tipo de espacios, el interés excesivo por lo afectivo y lo sentimental, la explotación de la intimidad, el querer ver excesivo que lleva al medio a recrearse en los detalles más escabrosos, la mezcla de géneros y la suplantación de la labor de otros poderes e instituciones públicas.

Lo único que le falta a Una hora con la verdad para ser el perfecto reality, sin ningún defecto o mancha, es el directo y la interactividad. Las imágenes que se emiten, aunque terriblemente impactantes, muestran sucesos, vivencias, que han acontecido. No se pide al espectador que sea activo: que llame, escriba o envíe un correo al programa para ofrecer datos sobre los niños desaparecidos o sobre el asesino.

\section{REFERENCIAS}

Abril, G. (1995). La televisión hiperrealista, en Revista CIC (Cuadernos de Información y Comunicación) no 1, p. 93-104.

Adler, A. (1968). Conocimiento del hombre. Madrid: Editorial Espasa Calpe.

Castañares, W. (1995). Nuevas formas de ver, nuevas formas de ser: el hiperrealismo televisivo, en Revista de Occidente, no de Julio-agosto, p. 106-119.

Imbert, G. (2003). El Zoo Visual. Barcelona: Editorial Gedisa.

Imbert, G. (2005, 10 de enero). Telebasura. De la telerealidad a la teleficción. Diario El País.

Laviana, J. C. (1996). Los chicos de la prensa. Madrid: Editorial Nickel Odeón.

León, B. (Comp.) (2009). Telerrealidad. El mundo tras el cristal. Sevilla: Comunicación Social Ediciones y Publicaciones.

Postman, N. (1991). Divertirse hasta morir. Barcelona: Ediciones de la Catarata.

Saltzman, J. (2002). Introduction to the Image of the Journalist in Popular Culture. Consultado el 12 de Octubre del 2010, Disponible en:

www.ijpc.org/uploads/files/ijpcintro.pdf

Vargas-Llosa, M. (2009, agosto): El mundo en que vivimos [Versión electrónica], en Diario El País. Consultado 16 de Abril del 2011, Disponible en: www.elpais.com/articulo/opinion/mundo/vivimos/elpepiopi/20090823elpepiopi_2/Tes 
Paula Requeijo Rey 